\title{
Nitric oxide pathway-mediated relaxant effect of aqueous sesame leaves extract (Sesamum radiatum Schum. \& Thonn.) in the guinea-pig isolated aorta smooth muscle
}

\author{
André B Konan ${ }^{1}$, Jacques Y Datté*1 and Paul A Yapo ${ }^{2}$
}

Address: ${ }^{1}$ Laboratoire de Nutrition et Pharmacologie, Département BA-PA, UFR-Biosciences, Cocody University, Abidjan 22 BP 582 Abidjan 22 , Côte d'Ivoire and '2Laboratoire de Physiologie Animale, Pharmacologie et Phytothérapie Abobo-Adjamé University, Abidjan, Côte-d'Ivoire

Email: André B Konan - b_ak7@yahoo.fr; Jacques Y Datté* - dattejy@gmx.net; Paul A Yapo - angoue_yapo@yahoo.fr

* Corresponding author

Published: 27 May 2008

BMC Complementary and Alternative Medicine 2008, 8:23 doi:10.1 186/1472-6882-8-23
Received: 5 February 2008

Accepted: 27 May 2008

This article is available from: http://www.biomedcentral.com/I472-6882/8/23

(C) 2008 Konan et al; licensee BioMed Central Ltd.

This is an Open Access article distributed under the terms of the Creative Commons Attribution License (http://creativecommons.org/licenses/by/2.0), which permits unrestricted use, distribution, and reproduction in any medium, provided the original work is properly cited.

\begin{abstract}
Background: Sesamum radiatum Schum. \& Thonn. (Pedaliaceae) is an annual herbaceous plant, which belongs to the family Pedaliaceae and genus Sesamum. Sesame is used in traditional medicine in Africa and Asia for many diseases treatment. Sesame plant especially the leaves, seed and oil are consumed locally as a staple food by subsistence farmers. The study analyses the relaxation induced by the aqueous extract of leaves from sesame (ESera), compared with those of acetylcholine (ACh) in the guinea-pig aortic preparations (GPAPs), in order to confirm the use in traditional medicine for cardiovascular diseases.

Methods: The longitudinal strips of aorta of animals were rapidly removed from animals. The aorta was immediately placed in a Mac Ewen solution. Experiments were performed in preparations with intact endothelium as well as in aortae where the endothelium had been removed. The preparations were suspended between two L-shaped stainless steel hooks in a $10 \mathrm{ml}$ organ bath with Mac Ewen solution. The isometric contractile force of the aorta strips of guinea-pig were recorded by using a strain gauge. All both drugs caused concentrationdependent relaxations responses.

Results: The aqueous extract of leaves from sesame ESera $\left(I \times 10^{-7}-0.1 \mu \mathrm{g} / \mathrm{ml}\right)$ caused a graded relaxation in GPAPs with intact endothelium, with a $\mathrm{EC}_{50^{-}}$-value of $\mathrm{I} \times 10^{-4} \mathrm{\mu g} / \mathrm{ml}$. The same effect was observed with $\mathrm{ACh}(7$ $\left.\times 10^{-2} \mathrm{nM}-7 \times 10^{-1} \mu \mathrm{M}\right)$, which caused relaxation in a concentration-dependent manner. The relaxation in response to ESera and, like that to ACh in GPAPs without endothelium, was fully abolished. Destruction of the endothelium or incubation with the nitric oxyde synthase inhibitor (L-NNA) significantly enhanced the inhibition of the relaxation response to ESera. Moreover, all concentrations induced vasoconstrictions. However, L-NNA produced a significant displacement to the right (about 65 -fold) of the relaxation response to ESera. Similar results were obtained with ACh. Both diclofenac and tetra-ethyl-ammonium (TEA) pretreatment of GPAPs induced a suppression of the relaxation caused by ESera, and produced a very significant rightward shifts of the CRC (16fold) for diclofenac and increase the Emax. In contract, the relaxation caused by ACh was not significantly affected by diclofenac or by TEA.
\end{abstract}

Conclusion: Thus, the present results indicate clearly that the nitric oxide largely contribute to the relaxation effect of Esera and of ACh in GPAPs. In addition, their contractile effects are also mediated by cyclooxygenase activation, and probably the $\mathrm{K}+$ channels involvement, that confirm the use of various preparations of Esera for the treatments of cardiovascular diseases. 


\section{Background}

Sesamum radiatum Schum. \& Thonn. (Pedaliaceae), pantotropical plant was used in traditional Medicine to facilitate the delivery in pregnant women $[1,2]$. Our first investigation with the action of ESera in the cardiovascular system of mammalians showed that ESera as well as acetylcholine, induced arterial hypotension resulting from cardiodepression and vasorelaxation of rabbits and rats [3]. Indeed, Furchgott et al (1980) [4] showed the mechanism of acetylcholine on the vascular smooth muscle. The vasodilatation induced by acetylcholine depended on the functional integrity of the endothelium and implied an endothelial hyperpolarising factor (EDHF) and a release of nitric oxide (NO). For these authors, the releasing effects of acetylcholine were extended to other natural biological substances or from synthesis $[5,6]$.

In view of these findings, the current study pursued three aims. The first goal is to explore whether ESera is able to inhibit GPAPs contractile activity. The second aim was to compare ESera and ACh in their potency and efficacy to relax the contractile force in the presence of nitric oxide. The third aim of the study was to explore whether any effect ESera on aorta smooth muscle is exclusively due to activation of cyclooxygenase pathway in relationship with nitric oxide (NO) or whether there is also cholinoceptorindependent component. Finally, the present study is an approach to elucidate the mechanism underlying ESera's action in the vasoralaxation observed in GPAPs.

\section{Methods \\ Plant}

Sesamum radiatum (Schum.) Thonn. (Pedaliaceae) was collected in October 2005 from farms specialized in growing plants for scientific or medical purposes. The leaves of Sesamum radiatum were verified to be identical samples at the specimen herbarium of the Centre National Floristique de Côte d'Ivoire at Cocody University in Abidjan. Voucher specimen were preserved and catalogued in the same herbarium (Centre National Floristique). This pantropical plant was authenticated by a Botanic expert, Prof. Aké-Assi Laurent of Centre National Floristique, UFR-Biosciences, University of Cocody, in Abidjan, Côte d'Ivoire).

\section{Phytochemical screening}

The extract and its fractions were tested by Lieberman Bouchard, Ferric chloride, cyanidine stiasny and, ValserMeyer and Dragendorff Tests to determine the presence of strerols, phenolic compounds, flavonoids, Tannin and alkaloids, respectively.

\section{Preparation of extract of sesame leaves}

Sesamum radiatum leaves were stored in cellophane bags. The leaves collected were dried at room temperature
(Temperature: $27 \pm 3^{\circ} \mathrm{C}$ ). The powdered leaves (100 g) were first macerated for 24 hours in $n$-hexane to remove chlorophyll and other hexanosolubles substances. The residue was dried and extracted by vigorously shaking in bi-distilled water for 24 hours. After 2-h extraction and filtration, the filtrate was concentrated, by evaporation of the solvent. The drug (ESera) obtained was stored at $4{ }^{\circ} \mathrm{C}$ until use.

\section{Animals}

Guinea-pigs (Cavia porcellus), of both sexes weighing between $350 \mathrm{~g}$ and $400 \mathrm{~g}$, were obtained from the Animal House of the Laboratory of Nutrition and Pharmacology of UFR-Biosciences at Cocody university in Abidjan (Ivory Coast). The guinea-pigs were housed in a constant temperature rooms with a light/dark cycle of $14 / 10$ hours. The animals were fed and given water ad libitum until they were used.

\section{Preparation of the guinea-pig aorta}

After sacrifice of animals, by cervical dislocation, the aorta was rapidly removed, and after being freed from connective tissue, each aorta was cut into three longitudinal strips $(6-7 \mathrm{~mm})$. The aorta was immediately placed in a Mac Ewen solution (at room temperature) of the following composition $\left[(\mathrm{mM}): \mathrm{NaCl}: 130 ; \mathrm{KCl}: 2.5 ; \mathrm{CaCl}_{2}: 2\right.$; $\mathrm{NaH}_{2} \mathrm{PO}_{4}: 1.18 ; \mathrm{NaHCO}_{3}: 11.9 ; \mathrm{MgCl}_{2}: 0.24$; glucose: 2.2 gassed with $95 \% \mathrm{O} 2+5 \% \mathrm{CO} 2$ ]

Since it has been shown that endothelium can inhibit the vasorelaxator effect of acetylcholine in aorta preparations $[7,8]$, experiments were performed in preparations with intact endothelium as well as in aortae where the endothelium had been removed by gentle rubbing of the intimae with a wooden rod to avoid the inhibitory role of functional endothelium to acetylcholine and Esera. Each strip of aorta was cut into $6-7 \mathrm{~mm}$ length. The preparations were suspended between two L-shaped stainless steel hooks in a $10 \mathrm{ml}$ organ bath with Mac Ewen solution at $37^{\circ} \mathrm{C}(\mathrm{pH}=7.4)$. Each preparation was connected by a silk thread to a force transducer FT30 (Hugo Sachs electronic, Freiburg, Germany) and the isometric force was recorded by a pen-recorder Rikadenki (Freiburg, Germany) on paper enrolled at a speed of $2.5 \mathrm{~mm} / \mathrm{min}$. A resting tension of $1 \mathrm{~g}$ was maintained, this setting allowed for the optimum observation of maximal contractile response to drugs.

\section{Experimental protocol}

After the equilibration period of $60 \mathrm{~min}$, tissues were exposed to ESera, which was added to the bath by means of cumulative methods [9] and to depolarizing potassium solution to test the viability. In most cases, a maximal contractile response ranging from $0.8-1.1 \mathrm{~g}$ could be 
induced. The preparations with a response below $0.6 \mathrm{~g}$ were considered insufficiently viable and discarded.

The potassium solution ( $80 \mathrm{mM} \mathrm{K} \mathrm{K}^{+}$) had the same composition as the Mac ewen buffer used, except that $\mathrm{NaCl}$ had been completely replaced by an equimolar amount of $\mathrm{KCl}$. Once the contraction had reached a plateau, the preparations were washed with Mac Ewen solution four times and left a further 40 min equilibration period at a re-adjusted tension of $1 \mathrm{~g}$.

To avoid tachyphylaxis, only a single cumulative concentration-response curve (CRC) for drugs was obtained in each preparation. Appropriate controls were run at the same time in different strips obtained from the aorta.

At the end of each experiment, after the drugs had been washed-out with Mac Ewen solution four times, acetylcholine $(1 \mu \mathrm{M})$ was added when the maximal response to noradrenaline $(0.4 \mu \mathrm{M})$ had been obtained, in order to assess the presence or absence of functional endothelium. A rapid and marked reduction of noradrenaline induced tone was taken evidence that a significant amount of functional endothelium was present. The absence of relaxant response was taken as indicative of the disappearance of functional endothelium $[8,10]$.

\section{Influence of the endothelium on the effects of Esera}

After the equilibration period of at least $60 \mathrm{~min}$, preparations with or without endothelium were exposed to ESera, which was added to the bath by means of a cumulative method [9], cumulative CRCs for Esera $\left(1 \times 10^{-7}-0.1 \mu \mathrm{g} /\right.$ $\mathrm{ml})$ or ACh $\left(1 \times 10^{-5}-0.1 \mu \mathrm{g} / \mathrm{ml}\right)$ were constructed in both endothelium-intact and endothelium-denuded aortic preparations of the same aorta. The drugs were then washed out with Mac Ewen solution four times. Subsequently, noradrenaline $(1 \mu \mathrm{M})$-induced contractions were imposed and ACh $(1 \mu \mathrm{M})$ was added to test whether functional endothelium was present.

\section{Influence of the nitric oxide (NO) synthesis inhibitor on the effects of Esera}

After equilibration, GPAP were exposed to a nitric oxide (NO) synthesis inhibitor; $\mathrm{N}^{\omega}$-Nitro-L-Arginine (L-NNA) at a concentration of $50 \mathrm{nM}$ for $30 \mathrm{~min}$. Cumulative CRCs of ESera were obtained in the presence of the nitric oxide inhibitor.

\section{Influence of the cyclooxygenase inhibitor on the effects of Esera}

After equilibration, the preparations were exposed to a cyclooxygenase inhibitor diclofenac at a concentration of $30 \mathrm{nM}$ for $30 \mathrm{~min}$. Cumulative CRCs of Esera were obtained in the presence of the cyclooxygenase inhibitor.

\section{Influence of the non selective potassic channels blocker on the effects of Esera}

After equilibration, the preparations were exposed to non selective potassium channels blocker the Tetra-ethylammonium (TEA) at a concentration of $50 \mathrm{nM}$ for 30 min. Cumulative CRCs of Esera were obtained in the presence of TEA.

\section{Chemicals used}

The acetylcholine and the $\mathrm{N}^{\omega}$-Nitro-L-Arginine were purchased from Sigma Company (St Louis, Mo, USA). Diclofenac and Tetra-ethyl-ammonium were provided from Sigma-Aldrich (Switzerland). All drugs were dissolved in saline.

\section{Statistics analysis}

Responses were expressed as absolute changes in mg of tension. Data are expressed as means \pm SEM obtained from $n$ separate experiments. Statistical analysis of the results was determined by using the unpaired Student's $t$ test. $p<0.05$ or less was considered as indicative of significance. The $\mathrm{EC}_{50}$ (i.e. the concentration of ESera or drug causing half maximum response) values were determined from individual experiments for the complete agonist concentration-response curves by figures carried out respectively using the software GraphPad Prism (San Diego, California, USA). The $\mathrm{EC}_{50}$ values are reported as geometric means accompanied by their respective 95\% confidence limits. All other reported results are means \pm s.e.m.

\section{Results}

\section{Phytochemical screening}

Phytochemical study that the sesame plant is rich in phenolic compounds (phenols, lignans and flavenoids). Sterols were also found in aqueous extract and its fractions.

\section{Extract of Sesamum radiatum Schum. \& Thonn. (ESera) induced contractions in endothelium-denuded guinea-pig aortic preparations}

In control conditions, regular contractile activity of the isolate aorta was recorded which were constant in all experiments and were not influenced by the addition of vehicle (Mac Ewen's solution (original tracing not shown).

In endothelium-intact GPAPs, ESera applied in a concentrations range from $1 \times 10^{-7}$ to $10^{-1} \mu \mathrm{g} / \mathrm{ml}$ caused relaxation of aorta preparations, in a concentration-dependent manner. The calculated means EC50 (95 \% confidence limits) and maximum relaxations for this effect were: $1 \times$ $10^{-4} \mu \mathrm{g} / \mathrm{ml}$. Concentrations of $1 \times 10^{-7} \mu \mathrm{g} / \mathrm{ml}$ and of $10^{-1}$ $\mu \mathrm{g} / \mathrm{ml}$ induced relaxations of $69.6 \pm 9 \mathrm{mg}$ and of $174.2 \pm$ $5,8 \mathrm{mg}$, respectively. Similar observations were obtained in the presence of acetylcholine. Both ESera and acetyl- 


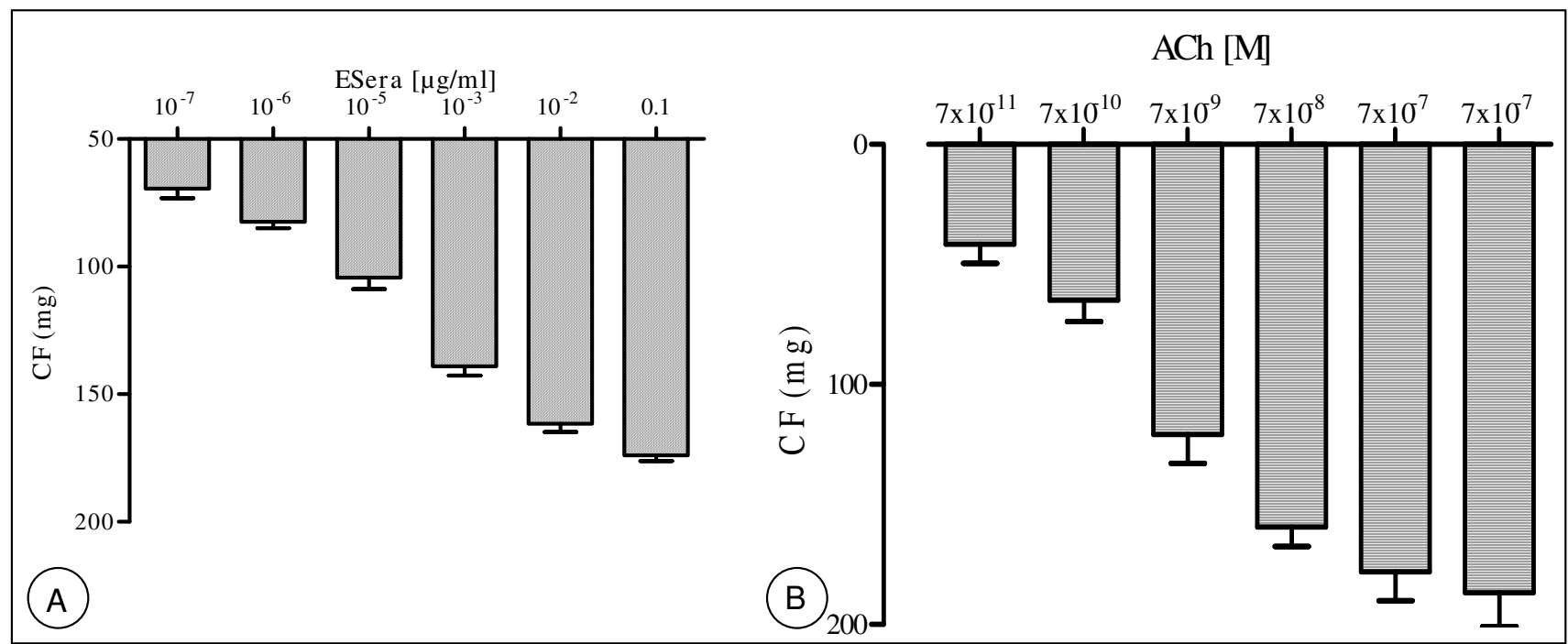

Figure I

Mean relaxant concentration-response curve for the effect of the extract of Sesamum radiatum Schum. \& Thonn (A) and for acetylcholine (ACh, B) in the guinea-pig isolated aorta preparations with endothelium. Data are shown as mean \pm s.e.m., expressed as the absolute values of percentage of the maximal response of $n$ experiments $(n=4-6, p<0.05)$.

choline on the relaxation of GPAPs was depicted on Fig. $1 \mathrm{~A} \& 1 \mathrm{~B}$.

Figure 1B illustrates the effect of acetylcholine (ACh) on the activity of GPAPs. ACh $\left(7 \times 10^{-2} \mathrm{nM}-7 \times 10^{-1} \mu \mathrm{M}\right)$ caused relaxation, in a concentration-response manner $\left(\mathrm{EC}_{50^{-}}\right.$-value $\left.=5.5 \mathrm{nM}\right)$. ACh at concentrations of $7 \times 10^{-2}$
$\mathrm{nM}$ and $0.7 \mu \mathrm{M}$ induced relaxation of endothelium-intact GPAPs for $41.7 \pm 8 \mathrm{mg}$ and for $187 \pm 12 \mathrm{mg}$, respectively.

In endothelium-denuded GPAPs, ESera in the same concentrations range induced contractions of isolated aortae. Concentration of ESera of $0.1 \mu \mathrm{g} / \mathrm{ml}$ induced a contractile force of $90.6 \pm 6 \mathrm{mg}$ (Fig. 2A). Contractions were obtained with ACh in the same preparations, which induced con-

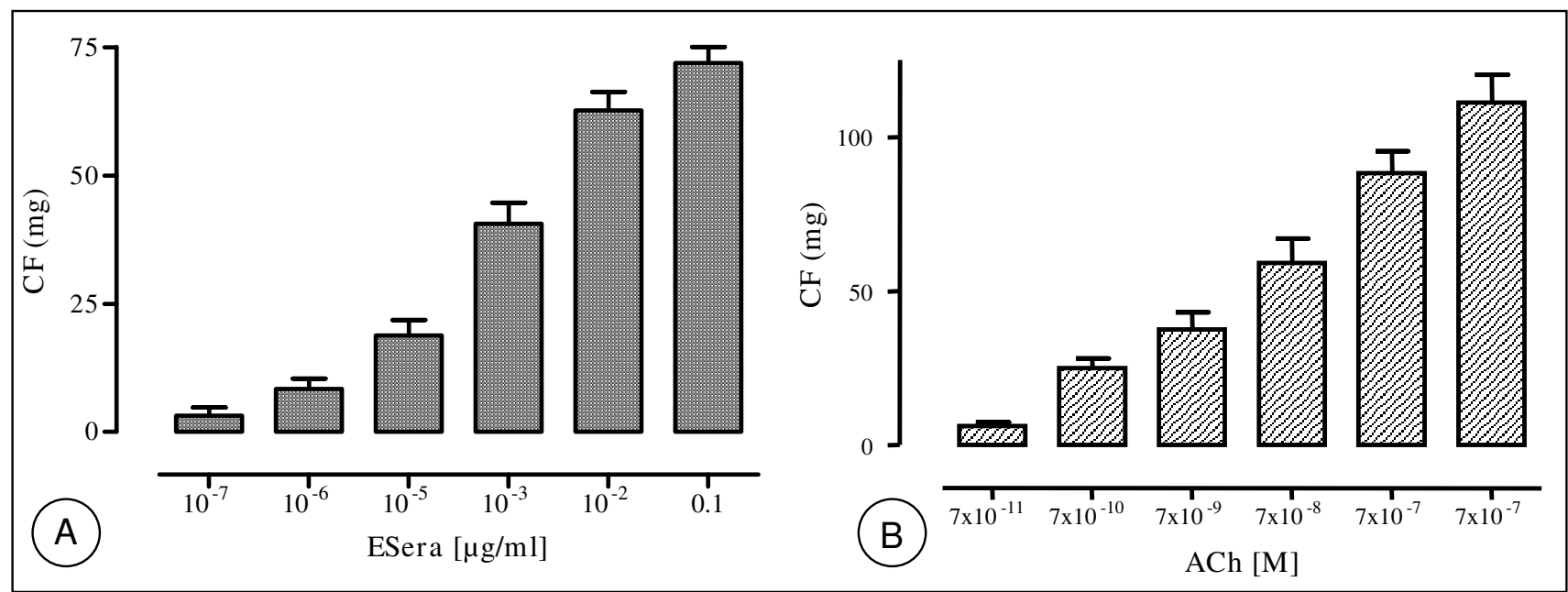

Figure 2

Mean relaxant concentration-response curve for the effect of the extract of Sesamum radiatum Schum. \& Thonn (A) and of acetylcholine $\mathbf{A C h}(\mathbf{B})$ in the guinea-pig isolated aorta preparations without endothelium. Data are shown as mean \pm s.e.m., expressed as the absolute values of percentage of the maximal response of 4 experiments $(p<0.05)$. 
centration-dependently contractions of endotheliumdenuded GPAPs. Concentration of $7 \times 10^{-2} \mathrm{nM}$ induced a contractile force of $111.9 \pm 9 \mathrm{mg}$ (Fig. 2B).

Inhibitory effects of L-N omega-Nitro- Arginine on ESerainduced vasorelaxation in guinea-pig aorta strips

Our previous experiments showed that ESera and ACh induced vasorelaxation of endothelium-intact guinea-pig aorta smooth muscle. In order to justify the involvement of the possible modulation by the endothelium of the contractile responses to ESera, L-NNA was used.

L-NNA (50 nM) shifted the CRCs for ESera concentrationdependently in endothelium-intact GPAPs to the right $\left(\mathrm{EC}_{50}\right.$-value $\left.=7.4 \times 10^{-4} \mu \mathrm{g} / \mathrm{ml}\right)$. However, the E-maxvalue was greatly attenuated of $71 \%$. High concentration of ESera $(0.1 \mu \mathrm{g} / \mathrm{ml})$ caused a significant reduction of the maximum relaxation $(174.2 \pm 5.8 \mathrm{mg})$ by the nitric oxide synthase inhibitor, to $50 \pm 4 \mathrm{mg}$ (Fig. 3A). Similar results were obtained with ACh. Indeed, L-NNA (50 nM) caused a rightward shift of the CRCs of ACh in endotheliumintact GPAPs (EC50-value $=36 \mathrm{nM})$. ACh $(0.7 \mu \mathrm{M})$ induced a relaxant effect of $187 \pm 12 \mathrm{mg}$ (Figure $3 \mathrm{~B}$ ) and a decrease of this effect induced by ACh to $45 \pm 6 \mathrm{mg}$ (an inhibition of relaxation of $75 \%$ ).

\section{Inhibitory effects of diclofenac or tetra-ethyl-ammonium} on ESera-induced vasorelaxation in guinea-pig aorta strips Previous studies of the effects of ESera were carried out on the cardiac muscle of rat in the presence of the atropine, antagonist of the muscarinic cholinoceptors. This study showed a partial cholinergic antagonist action of ESera [2].

The relaxations induced by Esera in GPAPs with endothelium were antagonized in a concentration-dependent and reversible manner by both diclofenac (cyclooxygenase inhibitor) and TEA (non-selective $\mathrm{K}^{+}$channel blocker).

The diclofenac (30 $\mathrm{nM}$ ) pre-treatment of endotheliumintact GPAPs caused ESera-induced vasocontriction. Diclofenac (30 nM) shifted the CRCs for ESera concentration-dependently in endothelium-intact GPAPs to the right $\left(\mathrm{EC}_{50}\right.$-value $\left.=1.2 \times 10^{-5} \mu \mathrm{g} / \mathrm{ml}\right)$. The contractile force was $90 \pm 6 \mathrm{mg}$, when ESera applied at a concentration of $0.1 \mu \mathrm{g} / \mathrm{ml}$ (Figure 4A). However, the same pre-treatment with diclofenac unaffected the ACh-induced relaxation of endothelium-intact GPAPs $\left(\mathrm{EC}_{50}=7.2 \mathrm{nM}\right)$. The value of the vasorelaxation was $125 \pm 7.8 \mathrm{mg}$ at a ACh's concentration of $0.7 \mu \mathrm{M}$. In contract, diclofenac did not significantly affect the relaxation induced by ACh.

In endothelium-intact GPAPs ESera-induced relaxation was significantly affected by the potassium channels blocker TEA ( $50 \mathrm{nM}$ ), but was potentiated by the cyclooxygenase inhibitor, diclofenac (30 $\mathrm{nM})$.

In endothelium-intact GPAPs, TEA at the same concentration inhibited totally the vasodilatory action to ESera. The CRC for ESera was shifted to the right $\left(\mathrm{EC}_{50}\right.$-value $=1.2 \times$

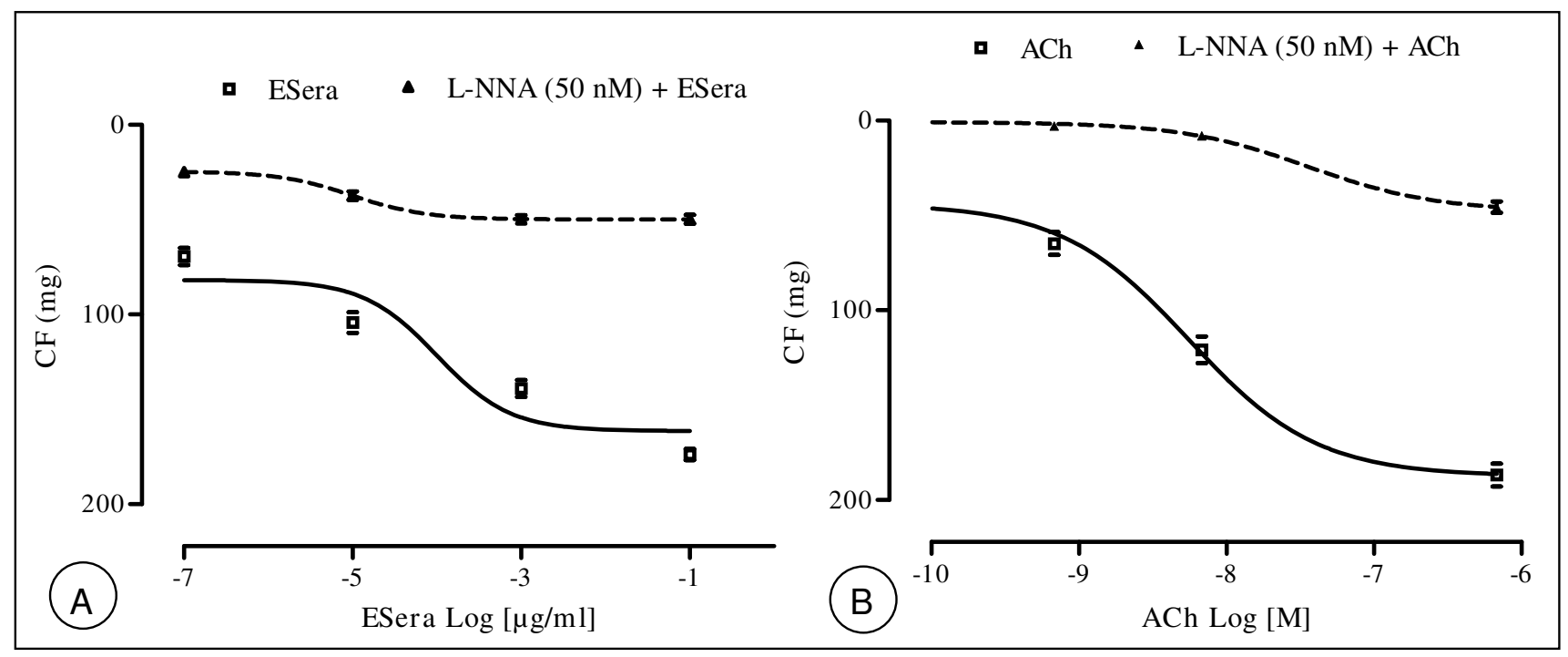

\section{Figure 3}

Mean relaxant concentration-response curve for the extract of Sesamum radiatum Schum. \& Thonn in endothelium-intact $(\mathbf{A})$ or in endothelium-denuded (B) guinea-pig isolated aorta preparations in the absence ( $\square$ ) and in the presence ( ) of L-NNA. Data are shown as mean \pm s.e.m., expressed as the absolute values of percentage of the maximal response of $n$ experiments ( $n$ $=4-6, \mathrm{p}<0.05)$. 


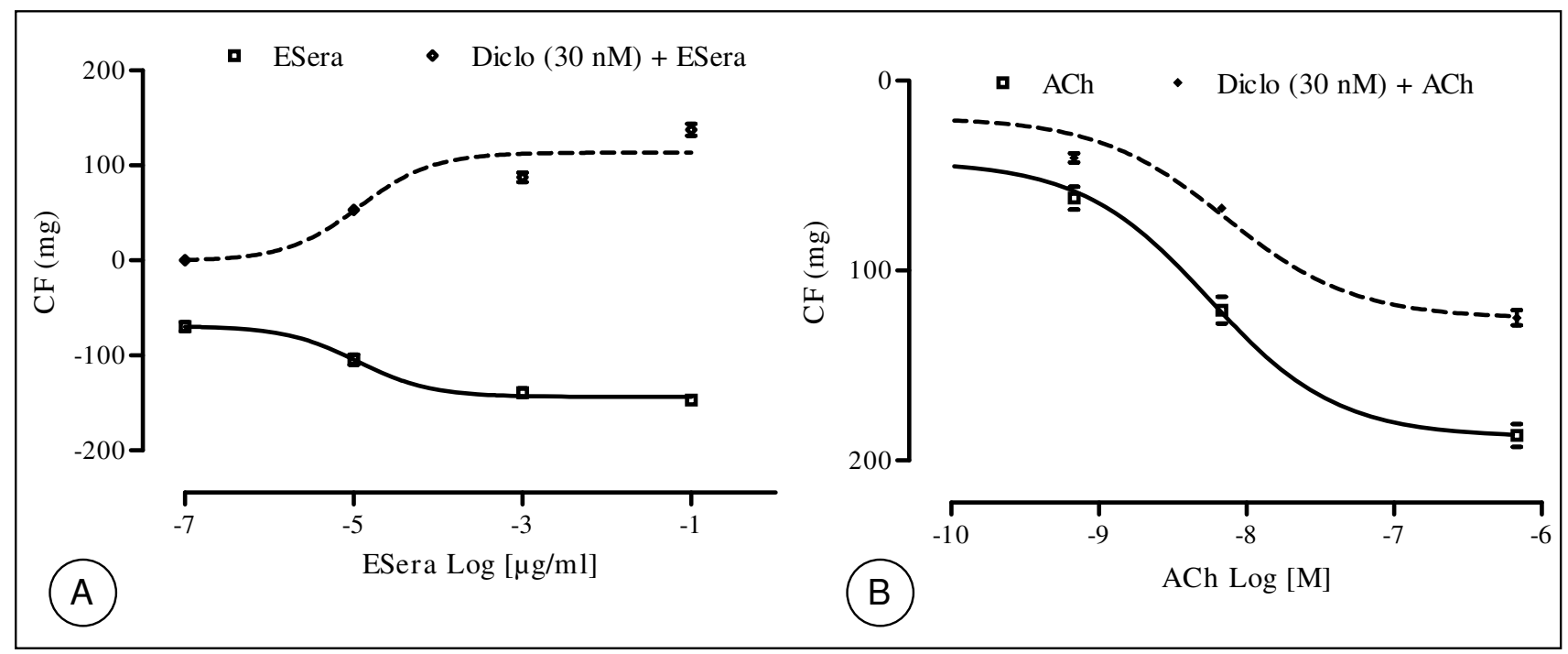

\section{Figure 4}

Mean relaxant concentration-response curve for the effect of extract of Sesamum radiatum Schum. \& Thonn (A) and of acetylcholine (B) in endothelium-intact guinea-pig isolated aorta preparations in the absence $(\square)$ and in the presence $(\diamond)$ of diclofenac. Data are shown as mean \pm s.e.m., expressed as the absolute values of percentage of the maximal response of $n$ experiments $(n=6, p<0.05)$.

$10^{-2} \mu \mathrm{g} / \mathrm{ml}$, Fig. 5A). In contrast, TEA caused slightly a rightward shift of the CRCs of ACh-induced relaxation in a concentration-response manner $\left(\mathrm{EC}_{50}\right.$-value $=9.2 \mathrm{nM}$, Fig. 5B). Interestingly, neither TEA nor diclofenac interfered significantly with the relaxation produced by ACh.

\section{Discussion}

Herbal preparations are used since ancient times to maintain health. Also, herbal preparations, if taken in appropriate dose, can lead to a better option for curing various aliment $[11,12]$.

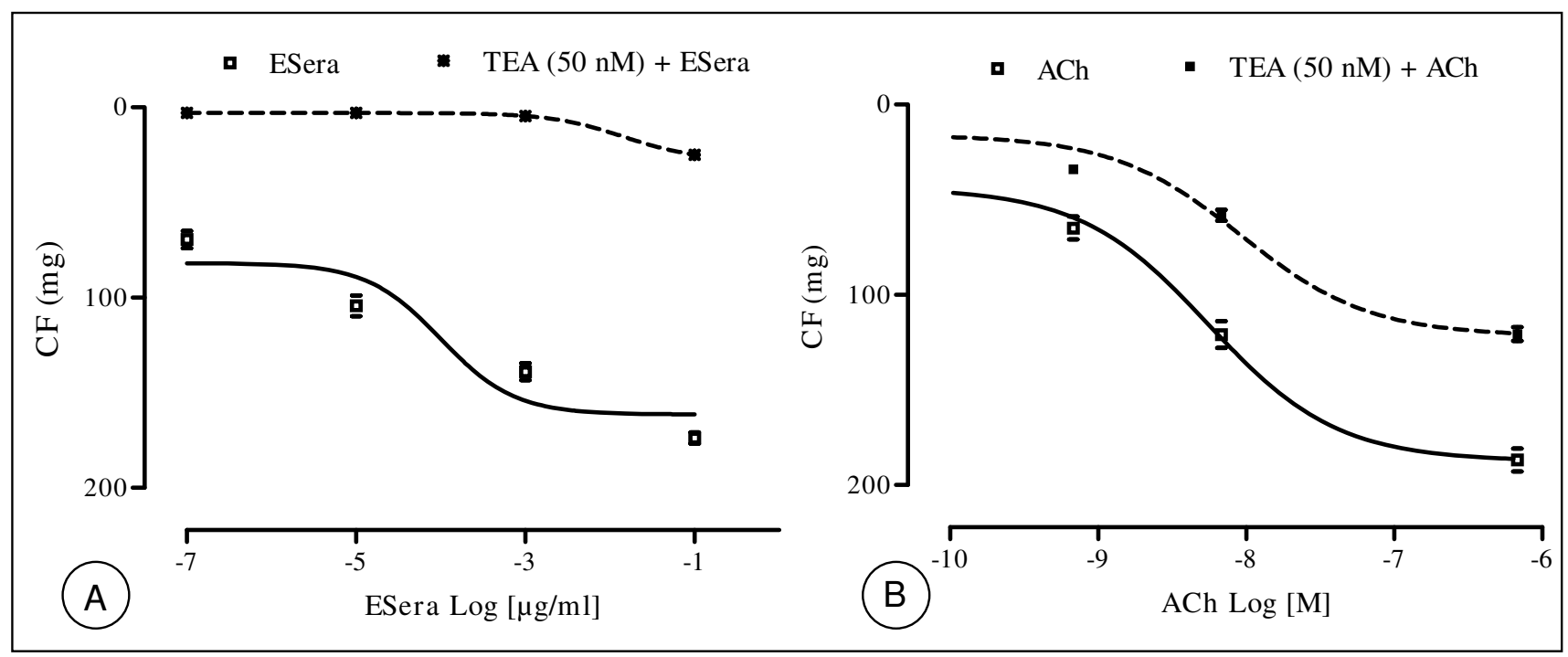

Figure 5

Mean relaxant concentration-response curve for the effect of extract of Sesamum radiatum Schum. \& Thonn (A) and of acetylcholine (B) in endothelium-intact guinea-pig isolated aorta preparations in the absence ( $\square$ ) and in the presence ( ) of TEA. Data are shown as mean \pm s.e.m., expressed as the absolute values of percentage of the maximal response of $n$ experiments ( $n$ $=6, p<0.05)$. 
The results of present study have demonstrated that ESera, besides inducing concentration-dependent relaxation in endothelium-intact GPAPs, at the same concentrations produces concentration-dependent contraction in either endothelium-denuded GPAPs or in the presence of nitric oxide synthesis inhibitor. Esera-induced relaxations in GPAPs with endothelium-intact are counteracted by endothelium.

Leaves of $S$. radiatum are used traditionally by patients in West Africa and are taken as water decoction [13]. Due to this reason the leaf juice of the plant was evaluated and the data also confirmed the traditional indications. Early investigations $[2,14]$ on the antihypertensive properties of the extracts of $S$. radiatum leaves by other authors also substantiate the results of our studies in Rabbits [3].

It seems likely that the endothelium-induced inhibition of ESera-effects is mediated by the endogenous vasodilator endothelium derived relaxing factor (EDRF) $[10,11]$. EDRF is assumed to be identical with NO or a closely related compound and vascular endothelial cells are known to synthesize NO $[16,17]$.

The releasing mediators are, for the majority, intrinsically diminishing vascular smooth muscle tone. The endothelial cells synthesize, according to stimuli, of the molecules to the vasorelaxant character such NO, protaglandins $\left(\mathrm{PGE}_{2}\right)$ with are releasing endothelial factors (EDRF) and the endothelial hyperpolarize factor (EDHF) [18-22].

Our findings are the first demonstration of endotheliumintact contractions to ESera in GPAPs.

Sesame had been shown to possess multiple health benefits, both alone and in synergistic combination with others compounds. By influencing pharmacological processes in the body, sesame and its lignans promise to help reduce risk for many of today's most common diseases, including heart disease, obesity, arterial hypertension and inflammatory disorders [23-31].

On the other hand, the TEA and the diclofenac differently affect the contractile activity induced either by ACh or by ESera. In separate experiments, after the first CRC of ESera had been obtained in endothelium-intact, $30 \mathrm{nM}$ diclofenac or 50 nM TEA were added and then the second CRC was contracted. It was fund that the maximal responses of second curves were increased in the presence of either antagonist. Diclofenac slightly shifted the second curves of ACh to the right, whereas it had no significant effect on the curves compound. These data, taken together with other results in this study, suggest that the contractile response to ESera is mediated by cyclooxygenase-receptors. Modulating factors which influence these parameters can be released from endothelium or from smooth muscle cells.

The prostaglandins as well as indometacin, a powerful antagonist of the cyclooxygenase did not affect relaxation in response to ACh $[32,33]$.

Destruction of the endothelium or inhibition of NO synthesis significantly enhanced the response to ESera in this preparation. Moreover, similar results were obtained with cyclooxygenase-inhibition or $\mathrm{K}^{+}$channels blocker were obtained with Chen et al. [34] and Niu et al. [35] suggest that the endothelium-denuded affect by $\mathrm{NO}$ via $\mathrm{K}^{+}$channels involvement cyclooxygenase pathways.

Our study indicated a significant myorelaxant and supports the traditional use of fresh leaves by Ivorian physicians.

In conclusion, on the basis of beneficial effect of ESera in the literature and our own results of the experiments in the extract of the same species ESera induces a decrease of vascular tone. Once found ESera may be incorporated as antihypertensive agent for the improvement of the patients suffering from cardiovascular diseases.

Chemical and pharmacological studies are now in progress to isolate and to characterize the constituents responsible for such effects, and also to investigate in more detail the mechanisms underlying the relaxant action of the active principle (s) of ESera in GPAPs.

\section{Competing interests}

The authors declare that they have no competing interests.

\section{Authors' contributions}

All authors contributed equally in the study.

\section{Acknowledgements}

The authors are indebted to Professor Aké-Assi Laurent (Laboratory of Botany, Unité de Formation et de Recherche -Biosciences, University of Cocody at Abidjan, Ivory Coast) for botanical identification of Sesamum radiatum Schum. \& Thonn. (Pedaliaceae).

\section{References}

I. Gautier-Béguin D: Plantes de cueillette à utilisation alimentaire en Côte d'Ivoire Centrale. Boissiera 1992, 46:2 II-219.

2. Konan BA, Datté JY, Offoumou AM: Action of the aqueous extract of Sesamum radiatum Schum. \& Thonn. (Pedaliaceae) on the cardiovascular system of mammalians: Hypotensive effect. Current Bioactive Compound 2006, 2:263-267.

3. Vanhoutte PM, Rubanyi GM, Miller VM, Houston DS: Modulation of vascular smooth muscle contractility by the endothelium. Ann Rev Physiol 1986, 48:307-320.

4. Furchgott RF: Studies on relaxation of rabbit aorta by sodium nitrite: the basis for proposal that the acid-activable inhitory factor from bovine retractor penis is inorganic nitrite and the endothélium-derived relaxing factor is nitric oxide. In Vasodilatation: vascular smooth muscle, peptides, autonomic nerves and 
endothélium Edited by: Vanhoutte PM. New York: Raven Press; |988:40|-4I4.

5. Lüscher TF: Endothelial vasoactive substances and cardiovascular disease. Basel: S Karger; | 988: I- | 30.

6. Angelis AD, Rinaldi B, Capuano A, Rossi F, Filippelli A: Indomethacin potentiates acetylcholine-induced vasodilatation by increasing free radical production. $\mathrm{Br} J$ Pharmacol 2004, 1 42: $1233-1240$.

7. Van Heiningen PN, Van Zwieten PA: Influence of the endothelium on $\mathrm{Ca}^{2+}$ dependency of angiotensin II-induced contractions of rat aortic rings. Fundam Clin Pharmacol 1993, 7:227-233.

8. Datté JY, Gohlke P, Pees C, Ziegler A: Short treatment of normotensive and hypertensive rat by angiotensin II and nitric oxide inhibitor induce increase of noradrenaline sensitivity in isolated portal vein preparations. Pharmacol Research 2000, 4I:64I-647.

9. Van Rossum : Cumulative dose-reponse curves. II. Technique for making of dose-reponse curves in isolated organs and the evolution of drugs parameters. Arch Int Pharmacodyn Ther 1963, I 43:299-330.

10. Datté JY, Yapo AP, Offoumou AM: Nitric oxide on 5-hydroxytryptamine induced vasoconstrictions of isolated smooth muscle. Pharmacological Reports 2005, 57: I 13-120.

II. Thompson LU, Robb P, Serraino M, Cheung F: Mammalian lignan production from varous foods. Nutr Cancer 1991, 16:43-52.

12. Ogungbenle HN, Oshodi AA, Oladimeji MO: Effect of salts on the functional properties of benniseed (Sesamum radiatum) seed flour. Int J Food Sci Nutr 2002, 53:5-14.

13. Shittu LAJ, Bankole MA, Oguntola JA, Ajala O, Shittu RK, Ogundipe OA, Bankole MN, Ahmed T, Ashiru OA: Sesame leaves intake improve and increase epididymal spermatocytes reserve in adulte male Sprague Dawley rat. Sci Res Essay 2007, 2:3 I 9-324.

14. Bankole MA, Shittu LAJ, Ahmed TA, Bankole MN, Shittu RK, Kpela T, Ashiru OA: Synergistic antimicrobial activities of phytooestrogens in crude extracts of two sesame species agains some common pathogenic microorganisms. Afr J Trad CAM 2007, 4:427-433

15. Gruetter CA, Ryan ET, Lemke SM, Bailly DA, Fox MK, Schoepp DD: Endothelium-dependent modulation of angiotensin IIinduced contraction in blood vessels. Eur J Pharmacol 1988, 146:85-95.

16. Palmer RM], Ashton DS, Moncada S: Vascular endothelial cells synthesize nitric oxide from L-arginine. Nature 1988, 333:664-666.

17. Bonnefont-Rousselot D, Peynet J, Beaudeux J-L, Thérond P, Legrand $A$, Delattre J: Stress oxidant, fonctions vasculaires et athérosclérose. Nutrition clinique et métabolisme 2002, 16:260-267.

18. Furchgott RF, Vanhoutte PM: Endothelium-derived and contracting factors. FASEB $\int$ 1989, 3:2007-2018.

19. McGuire J], Ding $H$, Triggle CR: Endothelium-derived relaxing factors: a focus on endothelium-derived hyperpolarizing factor. Can J Physiol Pharmacol 200 I, 79:443-470.

20. Félétou M, Busse R, Edwards G, Fleming I, Weston AH, Vanhoutte PM: Dialogue entre cellules endothéliales et cellules musculaires lisses. M/S 2003, 19:1242-1250.

21. Achike FI, Kwan CY: Nitric oxide, human diseases and herbal products that act on NO pathway. Clin Expt Physiol Pharmacol 2003, 30:606-615.

22. Lee CC, Chen PR, Lin S, Tsai SC, Wang BW, Chen WW, Tsai CE, Shyu KG: Sesamin induces nitric oxide and decreases endothelin-I production in HUVECs: possible implication for its antihypertensive effect. Journal of Hypertension 2004 23:2329-2338.

23. Hirose N, Doi F, Akawaza K, Chijima K, Sugano M, Akimoto K Shimizu S, Yamada H: Suppressive effect of sesamin against $\mathbf{7}$, 1 2-dimethyl-benz-[a] anthracene-induced rat mammary carcinogenesis. Anticancer Res 1992, I 2: |259-| 266.

24. Kita S, Matsumura Y, Morimoto S, Akimoto K, Furuya M, Oka N, Tanaka T: Antihypertensive effect of sesamin. II. Protection against two-kidney, oneclip renal hypertension and cardiovascularhypertrophy. Biol Pharm Bull 1995, I 8: | 283-1285.

25. Matsumura Y, Kita S, Tanide T, Taguchi Y, Morimoto S, Akimoto K, Tanaka T: Antihypertensive effect of sesamin. III. Protection against development and maintenance of hypertension in stroke-prone spontaneously hypertensive rats. Biol Pharm Bull 1998, $21: 469-473$
26. Matsumura Y, Kita S, Ohgushi R, Okui T: Effects of sesamin on altered vascular reactivity in aortic rings of deoxycorticosterone acetate-salte-induced hypertensive rat. Biol Pharm Bull 2000, 23: $104 \mid-1045$

27. Umeda-Sawada R, Ogawa M, Nakamura M, Igarashi O: Effect of sesamin on mitochondrial and peroxisomal beta-oxidation of arachidonic and cicosapantaenoic acids in rat liver. Lipids 200I, 36:483-489.

28. Nakano D, Itoh C, Takaoka M, Kiso Y, Tsuruoka N, Tanaka T, Matsumura $Y$ : Antihypertensive effetc of sesamin. IV. Inhibition of vascular superoxide production by sesamin. Biol Pharm Bull 2002, 25: I247-1249.

29. Nakano D, Itoh C, Ishii F, Kawanishi H, Takaoka M, Kiso Y, Tsuruoka $\mathrm{N}$, Tanaka T, Matsumura $Y$, et al.: Effetc of sesamin on aortic oxidative stress and endothelial dysfunction in deoxycorticosterone acetate-salt hypertensive rats. Biol Pharm Bull 2003, 26: $1701-1705$.

30. Jeng KCG, Hou RCW: Sesamin and Sesamolin: Nature's therapeutic lignans. Current enzymes Inhibition 2005, I: I I-20.

3I. Tsuruoka N, Kidokoro A, Matsumoto I, Abe K, Kiso Y: Modulating effect of sesamin, a functional lignan in sesame seeds, on transcription levels of lipid- and alcohol-metabolizing enzymes in rat liver: a DNA microarray study. Biosci Biotechnol Biochem 2005, 69:179-188.

32. Furchgott RF, Zawadski JV: The obligatory role of endothelial cell in the relaxation of arterial smooth muscle by acetylcholine. Nature 1980, 93:515-524.

33. Pompermayer K, Assreuy J, Vieira MA: Involment of nitric oxide and potassium channels in the bradykinin-induced vasodilatation in the rat kidney perfused ex situ. Regul Pept 2002, 105:155-162.

34. Chen PR, Tsaï CE, Chang H, Liu TL, Lee CC: Sesamol induces nitric oxide release from human umbilical vein endothelial cells. Lipids 2005, 40:955-961.

35. Niu LG, Zhang MS, Liu Y, Xue W, Liu DB, Zhang J, Liang YQ: Vasorelaxant effect of taurine is diminished by tetraethylammonium in rat isolate arteries. Eur J Pharmacol 2008, 580:169-74.

\section{Pre-publication history}

The pre-publication history for this paper can be accessed here:

http://www.biomedcentral.com/1472-6882/8/23/prepub
Publish with Bio Med Central and every scientist can read your work free of charge

"BioMed Central will be the most significant development for disseminating the results of biomedical research in our lifetime. "

Sir Paul Nurse, Cancer Research UK

Your research papers will be:

- available free of charge to the entire biomedical community

- peer reviewed and published immediately upon acceptance

- cited in PubMed and archived on PubMed Central

- yours - you keep the copyright

Submit your manuscript here:

http://www.biomedcentral.com/info/publishing_adv.asp
BioMedcentral 